Richard F. McEllistrem FFARCSI, Joanne Schell, Kevin O'Malley MD PH D FRCPE FRCPI,

David O'Toole FFARCSI,

Anthony J. Cunningham FACA FFARCSI FRCPC

\title{
Interscalene brachial plexus blockade with lidocaine in chronic renal failure - a pharmacokinetic study
}

Plasma lidocaine concentrations, latency of onset, and duration of anaesthesia, were determined after interscalene brachial plexus block in 16 patients presenting for elective upper limb surgery. Eight patients had normal renal function and eight had chronic renal failure, as determined by creatinine clearance. Significantly higher plasma lidocaine levels were recorded ten minutes after infiltration in patients with chronic renal failure $(p<0.05) . C_{\max }$ plasma levels for normal patients $(5.6 \pm 1.1$ $\mu \mathrm{g} \cdot \mathrm{ml}^{-1}$ ) and for patients with chronic renal failure $\{6.6 \pm J .6$ $\mu \mathrm{g} \cdot \mathrm{ml}^{-1}$ ) were not significantly different. The latency of onset and duration of anaesthesia were similar in both groups. One per cent lidocaine solution may be administered to patients with normal and impaired renal function to provide effective brachial plexus blockade for short surgical procedures.

\section{Key words}

ANAESTHETIC TECHNIQUES, REGIONAL: brachial plexus block; ANAESTHETICS, LOCAL: lidocaine; KIDNEY: renal failure.

From the Departments of Anaesthesia and Clinical Pharmacology, Royal College of Surgeons in Ireland, Dublin, Ireland.

Address correspondence to: A. J. Cunningham, Department of Anaesthesia, Royal College of Surgeons in Ireland, St. Stephen's Green, Dublin 2.

This study was presented, in part, at the European Society of Regional Anacsthesia, Dublin, Scptember 1987 and at the Canadian Anacsthetists Socicty Annual Meeting, Halifax, June 1988. This study was supported by funding from the Jervis Street Hospital Trust Fund.
Brachial plexus block is an ideal form of anaesthesia for arterio-venous (A-V) fistula formation in patients with end-stage renal disease. Not only are the hazards of general anaesthesia avoided in already compromised patients but peripheral vasodilatation, due to associated sympathetic blockade, facilitates a successful surgical outcome.

In a study comparing lidocaine supraclavicular brachial plexus block in patients with normal and abnormal renal function, Bromage et al. ${ }^{1}$ demonstrated a 40 per cent reduction in the duration of blockade in renal failure patients. Postulated mechanism of action include biochemical and cardiovascular changes associated with chronic renal failure. However, Beauregard et $a l^{2}$ recently showed no difference in the duration of anaesthesia between normal and renal failure patients when using axillary brachial plexus blockade. No pharmacokinetic data exists on lidocaine after interscalene brachial plexus block in renal failure patients. Pharmacokinetic data on lidocaine in renal failure patients has been obtained following intravenous administration. These studies demonstrated that the clearance, terminal half-life and total volume of distribution were similar in both normal and chronic renal failure patients. ${ }^{3,4}$ However, to extrapolate these findings to patients receiving regional anaesthesia is not appropriate.

The objectives of this study were to compare the latency of onset and duration of anaesthesia in patients with normal and impaired renal function following lidocaine interscalene brachial plexus block and to compare the systemic absorption of the infiltrated drug.

\section{Methods}

Following institutional ethics committee approval and informed consent sixteen (ASA physical status I-III) patients ( 5 male, 11 female) undergoing interscalene brachial plexus block, to facilitate upper limb surgery, were studied. Eight patients had normal renal function (Group I) and Group II consisted of eight chronic renal failure patients undergoing A-V fistula formation. No 
clinical evidence of uraemic neuropathy was observed in Group II patients. Patients with a history of allergy to local anaesthetic agents or medication with $\mathrm{H}_{2}$ receptor or beta-adrenoceptor blocking drugs were excluded.

All patients had full preoperative blood count, urea and electrolytes, arterial blood gases, plasma proteins and creatinine clearance performed. All patients received diazepam $0.15 \mathrm{mg} \cdot \mathrm{kg}^{-1}$ orally two hours before surgery.

The interscalene approach to the brachial plexus was used as previously described. ${ }^{5}$ A stimulating needle electrode was used to produce biceps and brachialis contractions $\left(\mathrm{C}_{5}, \mathrm{C}_{6}\right.$ myotomes). Following location of the plexus $0.25 \mathrm{ml} \cdot \mathrm{cm}^{-1}$ height of lidocaine one per cent $\mathrm{HCl} \mathrm{BP}$ was injected over a 30 -second period.

Latency and duration of anaesthesia were determined by pin-prick. The latency time was assessed from commencement of injection of lidocaine to the development of pin-prick analgesia at the surgical site. The duration of analgesia was taken as time from development of analgesia at the surgical site until the first awareness of pain. Operative sites in both groups were within $\mathrm{C}_{5}, \mathrm{C}_{6}$ and $\mathrm{C}_{7}$ dermatomes of the forearm. Monitoring techniques included automated blood pressure recordings and continuous electrocardiographic display.

Ten $\mathrm{ml}$ venous blood aliquots were withdrawn from the contralateral antecubital fossa at $0,5,10,15,20,30$ and 60 minutes following local anaesthetic administration for local anaesthetic assay.

Following centrifugation the supernatant plasma was stored at $-20^{\circ} \mathrm{C}$ before lidocaine assay by a gas liquid chromatograph equipped with a six-foot column of three per cent OV 17 chromsorb WHP 100-120 mesh. The chromatograph was equipped with a nitrogen phosphate detector for lidocaine. Piviton was used as an intemal standard for lidocaine. Coefficients of variation (CV) of the chromatographic system were 1.96 per cent and
2.5 per cent for $2 \mu \mathrm{g} \cdot \mathrm{ml}^{-1}$ and $0.5 \mu \mathrm{g} \cdot \mathrm{ml}^{-1}$ samples respectively and standard deviations were $2.04 \pm 0.04$ $\mu \mathrm{g} \cdot \mathrm{ml}^{-1}$ and $0.048 \pm 0.012 \mu \mathrm{g} \cdot \mathrm{ml}^{-1}$.

The data are expressed as mean \pm standard deviation (SD). An unpaired Student's $t$ test was used for intergroup comparisons while repeated multivariate analysis of variance (MANOVA) was used to compare the values within a group. Probability values less than 0.05 were considered to be significant.

\section{Results}

There was no significant difference between the ages of both patient populations. Chronic renal failure patients were significantly more acidotic, had lower haematocrits and serum albumin levels (Table I). Chronic renal failure patients tended to have longer latency of onset and duration of action than normal patients, but these differences were not statistically significant (Table II). The mean duration of action did not exceed 60 minutes in either group, and the mean latency of onset time did not exceed ten minutes

Figure 1 illustrates the mean plasma lidocaine concentrations recorded up to 60 minutes following brachial plexus infiltration. Although the mean plasma lidocaine concentrations were higher in chronic renal failure patients, the difference was significant only at ten minutes following infiltration. The rate of systemic absorption of lidocaine is indirectly indicated by the log of plasma concentration at 5,10 and 15 minutes (Figure 2) and by the values of $\mathrm{C}_{\max }$. The rate of absorption was higher in patients with chronic renal failure but this difference was not significant.

The peak plasma lidocaine concentrations $\left(\mathrm{C}_{\max }\right)$ were recorded at 15 minutes following infiltration in both groups (Table II). All patients were haemodynamically stable and no patient developed toxic symptoms despite

TABLE I Patient demographics and laboratory assessment. Data expressed as mean \pm SD

\begin{tabular}{lcc}
\hline & $\begin{array}{c}\text { Group I } \\
\text { (normal renal function) }\end{array}$ & $\begin{array}{l}\text { Group II } \\
\text { (chronic renal failure) }\end{array}$ \\
\hline $\mathbf{n}$ & 8 & 8 \\
$\mathrm{M} / \mathrm{F}$ & $2 / 6$ & $3 / 5$ \\
Age $(\mathrm{Yrs})$ & $33.3 \pm 18.0$ & $47.4 \pm 17.7$ \\
Haematocrit & $0.36 \pm 0.03$ & $0.27 \pm 0.05^{*}$ \\
Haemoglobin $\left(\mathrm{gm} \cdot \mathrm{dl}^{-1}\right)$ & $12.5 \pm 0.98$ & $8.88 \pm 2.2^{*}$ \\
Albumin $\left(\mathrm{mmol} \cdot \mathrm{L}^{-1}\right)$ & $40.0 \pm 3.6$ & $37.0 \pm 2.3^{*}$ \\
$\mathrm{pH}$ & $7.4 \pm 0.02$ & $7.3 \pm 0.04^{*}$ \\
$\mathrm{HCO}{ }_{3}-\left(\mathrm{mmol} \cdot / \mathrm{L}^{-1}\right)$ & $22.4 \pm 1.2$ & $19.9 \pm 3.2^{*}$ \\
$\mathrm{~K}^{+}\left(\mathrm{mmol} \cdot \mathrm{L}^{-1}\right)$ & $3.75 \pm 0.3$ & $4.3 \pm 0.5 *$ \\
Serum creatinine $\left(\mu \mathrm{mol} \cdot \mathrm{L}^{-1}\right)$ & $70 \pm 3$ & $\mathbf{8 7 9} \pm 80$ \\
Creatinine clearance $\left(\mathrm{ml} \cdot \mathrm{min}^{-1}\right.$ ) & - & $5.99 \pm 0.63$ \\
\hline
\end{tabular}

$* p<0.05$. 


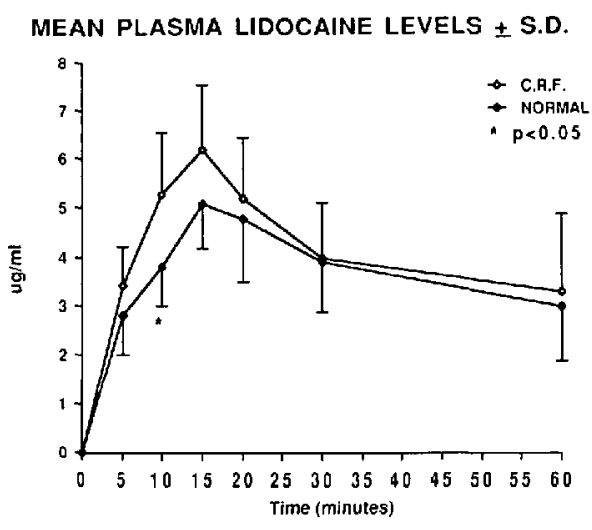

FIGURE 1 Mean plasma lidacaine concentrations $\pm S D$, at $0,5,10$, $15,20,30$ and 60 minutes following infiltration.

the high plasma lidocaine levels observed in both groups. All surgical procedures were completed uneventfully.

\section{Discussion}

In this study the systemic absorption of lidocaine following interscalene brachial plexus block was rapid and extensive. Absorption was more rapid in patients with chronic renal failure (Figure 2), but the peak plasma lidocaine concentrations $\left(C_{\text {max }}\right)$ of both groups were not significantly different. Latency of onset and duration of action were similar in both groups. Patients with chronic renal failure were more acidotic, anaemic and had lower serum albumin concentrations than patients with normal renal function. Although high plasma lidocaine concentrations were observed in both groups no patient developed toxic symptoms.

Plasma lidocaine concentrations following perineural injection are determined by the rate of systemic absorption, drug distribution and elimination. The systemic absorption of lidocaine following infiltration is determined mainly by the vascularity of the site injected ${ }^{6}$ Local tissue binding and $\mathrm{pH}$ effects also influence the

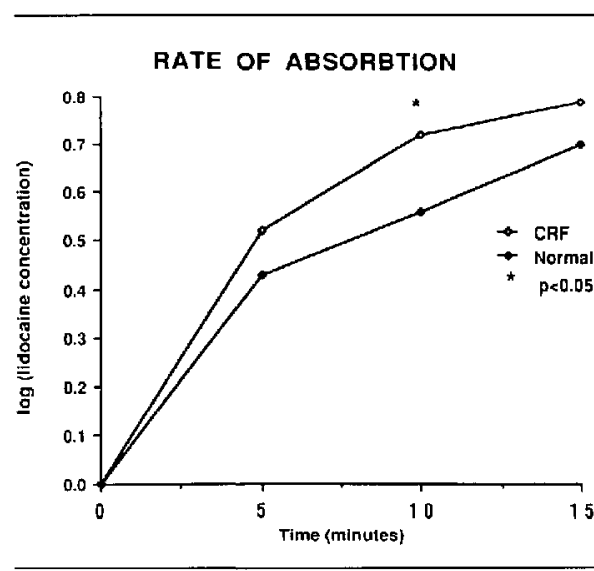

FIGURE 2 Log of plasma lidocaine concentration at 5,10 , and 15 minutes.

"washout" of lidocaine from perineural tissues. The weight and age of the adult patients studied, concentration of lidocaine and speed of injection have little effect on plasma lidocaine levels. ${ }^{6}$ High plasma lidocaine concentrations were observed in both groups of patients in this study. This can be accounted for by the high vascularity of the interscalene injection site. The faster rate of absorption and higher plasma lidacaine levels observed in chronic renal failure patients in this study may be explained by higher cardiac outputs and better tissue perfusion compared with normal renal function patients.?

Lidocaine hydrochloride is water soluble and exists in solution as ionized and non-ionized (lipid soluble) forms. The pKa of lidocaine is 7.9 and as this value is greater than physiological $\mathrm{pH}$, perineural lidocaine exists mainly in the ionized form.

Duration of anaesthesia of any local anaesthetic agent following perineural injection is directly related to the lipid solubility of that agent. ${ }^{8}$ In acidotic chronic renal failure patients, plasma $\mathrm{pH}$ is decreased and the fraction of ionized (lipid insoluble) lidocaine is thus increased. lonized (lipid insoluble) lidocaine penetrates the axonal

TABLE II Pharmacodynamic and pharmacokinetic data expressed as mean \pm SD

\begin{tabular}{lcl}
\hline & $\begin{array}{l}\text { Group I } \\
\text { (Normal renal function) }\end{array}$ & $\begin{array}{l}\text { Group II } \\
\text { (Chronic renal failure) }\end{array}$ \\
\hline Latency of onset (mins) & $8 \pm 2$ & $10 \pm 3$ \\
Duration of action (mins) & $46 \pm 17$ & $59 \pm 19$ \\
$C_{\max }\left(\mu \mathrm{g} \cdot \mathrm{ml}^{-1}\right)$ & $5.6 \pm 1.1$ & $6.6 \pm 1.6$ \\
Dose $\left(\mathrm{mg} \cdot \mathrm{kg}^{-1}\right)$ & $6.3 \pm 0.3$ & $6.7 \pm 0.4$ \\
\hline
\end{tabular}

${ }^{*} \mathrm{p}<0.05$. 
membrane much less efficiently than the non-ionized (lipid soluble) form, so duration of anaesthesia should be shorter in chronic renal failure patients. In this study we observed no significant difference between duration of anaesthesia for normal and chronic renal failure patients. This may be explained by examination of the mechanism of action of lidocaine. The non-ionized form on penetration of the neural membrane requilibrates with the ionized form intraneurally, which is the active blocker of nerve conduction. ${ }^{8}$ Metabolic acidosis as observed in chronic renal failure patients may increase the fraction of ionized lidocaine that is available inside the nerve for impulse blockade. This intraneural ion trapping may compensate for the decreased levels of perineural lipid soluble lidocaine seen in renal failure patients and could serve to explain why there was no significant difference in duration of anaesthesia in the two groups.

Following systemic absorption, lidocaine exists in the plasma in two forms; as free or unbound lidocaine and as lidocaine bound to plasma proteins. Alpha $a_{1}$ acid glycoprotein is the main plasma protein binding lidocaine following systemic absorption. ${ }^{9}$ Albumin binds lidocaine to a much lesser extent. Chronic renal failure patients have higher plasma levels of alpha $a_{1}$ acid glycoprotein than normal patients. ${ }^{10}$ Therefore, renal failure patients will have lower levels of unbound plasma lidocaine than normal patients. ${ }^{9}$ It is generally accepted that the unbound plasma lidocaine concentration correlates more closely to toxic effects than total plasma lidocaine concentrations. ${ }^{10}$ Renal failure patients with high total plasma lidocaine concentrations may have free or unbound plasma lidocaine concentrations within "non-toxic" limits. This would explain why renal failure patients in this study did not develop toxic symptoms when total plasma lidocaine concentrations were above threshold plasma concentrations associated with onset of central nervous system toxicity (minimal toxic concentrations). These values range from 5 to $10 \mu \mathrm{g} \cdot \mathrm{ml}^{-1}$ for lidocaine. The low serum albumin concentrations of renal failure patients may not be pharmacokinetically significant, although binding of lidocaine to albumin may decrease brain uptake of lidocaine. ${ }^{11}$

In this study high peak plasma lidocaine concentrations were measured 15 minutes following the administration of a $6-7 \mathrm{mg} \cdot \mathrm{kg}^{-1}$ lidocaine plain solution injection. The maximum recommended adult single dose of lidocaine without adrenaline has ranged from $300-500 \mathrm{mg} \cdot{ }^{12.13}$ No conclusive evidence exists to support a relationship between body weight, dosage and blood concentrations and to quote maximum doses in terms of $\mathrm{mg} \cdot \mathrm{kg}^{-1}$ may be erroneous.

Lidocaine without adrenaline was used in this study because an inadvertent intravascular injection of a local anaesthetic solution with adrenaline might have produced significant tachycardia and hypertensive responses in chronic renal failure patients. Also cardiovascular disturbances have been reported during brachial plexus blockade when doses of adrenaline greater than $200 \mu \mathrm{g}$ were used to provide vasoconstriction. ${ }^{14}$

A dose of $0.5 \mathrm{ml} \cdot$ inch $^{-1}$ height $\left(0.2 \mathrm{ml} \cdot \mathrm{cm}^{-1}\right)$ of local anaesthetic solution has been suggested for interscalene brachial plexus block. ${ }^{15}$ However, studies have demonstrated that $30 \mathrm{ml}$ of solution may be inadequate to ensure an effective block and $40 \mathrm{ml}$ has been used to provide plexus blockade. ${ }^{16.17}$ In this study $0.25 \mathrm{ml} \cdot \mathrm{cm}^{-1}$ height $\left(0.6 \mathrm{ml} \cdot\right.$ inch $\left.^{-1}\right)$ was used to provide effective interscalene brachial plexus blockade.

The implications for patient management from this study would suggest that diazepam $0.15 \mathrm{mg} \cdot \mathrm{kg}^{-1} \mathrm{PO}$ be administered two hours preoperatively to alter local anaesthetic seizure threshold and possibly prevent systemic toxicity. ${ }^{18}$ Also the use of lidocaine with adrenaline for brachial plexus blockade in normal patients must be recommended. Addition of 1:200,000 adrenaline significantly reduces the plasma level of lidocaine following interscalene brachial plexus block. ${ }^{16}$

In conclusion, plasma lidocaine concentrations following interscalene brachial plexus block in both groups were above minimal toxic concentrations. Despite high plasma lidocaine levels no patient developed symptoms of toxicity and all surgical procedures were completed uneventfully. Because interscalene block of the brachial plexus is associated with "toxic" plasma lidocaine concentrations, all patients should receive diazepam preoperatively and should be carefully monitored for evidence of systemic toxicity following lidocaine infiltration.

The mean duration of anaesthesia following lidocaine interscalene brachial plexus block did not exceed 60 minutes. Therefore interscalene brachial plexus block with lidocaine is an unsuitable technique for long surgical procedures. One per cent lidocaine solution will provide effective brachial plexus blockade for short surgical procedures in patients with normal and impaired renal function.

\section{References}

1 Bromage PR, Gertel $M$. Brachial plexus anesthesia in chronic renal failure. Anesthesiology 1972; 36: 488-93.

2 Beauregard L, Martin R, Tetrault JP. Brachial plexus block and chronic renal failure. Can J Anaesth 1987; 34: $\$ 118$

3 Thomson $P D$, Melmon KL, Richardson JA et al. Lidocaine pharmacokinetics in advanced heart failure, liver disease and renal failure in humans. Ann Intern Med 1973; 78 : $499-508$. 
4 Collinsworth KA, Strong $J M$, Atkinson $S R$. AJ, Winkle $R A$, Perlroth F, Harrison DC. Pharmacokinetics and metabolism of lidocaine in patients with renal failure. Clin Pharmacol Ther 1975; 18: 59-64.

5 Murphy TM. Nerve block of upper extremity. Miller RD (Ed). Anesthesia, 2nd ed. New York: Churchill Livingstone, 1986, 1015-1060.

6 Scon DB, Jebson PJR, Braid DP, Ortengeren B, Frisch $P$. Factors affecting plasma levels of lignocaine and prilocaine. Br $\mathrm{J}$ Anaesth 1972; 44: 1040-9.

7 Mostert JW, Evers $J$, Hobika GH et al. The haemodynamic response to chronic renal failure as studjed in the azotaemic state. Br J Anaesth 1970; 42: 397-411.

8 Cousins MJ, Phillips GD. Acute Pain Management 1st ed. New York: Churchill Livingstone Inc. 1986, 105-133.

9 Tucker GT. Phamacokinetics of local anaesthetics. Br J Aлaesth 1986; 58: 717-31

10 Pieper JA, Wyman MG, Goldreyer BN, Cannom DS, Slaughter RL, Lalka D. Lidocaine toxicity: effects of total versus free lidocaine concentrations. Circulation 1980; 62: 181 - .

11 Pardridge WM, Sakiyama R, Fierer $G$. Transport of propanolol and lidocaine through the rat blood-brain barrier. Primary role of globulin-bound drug. J Clin Invest 1983; 71: 900-908.

12 Cousins MJ, Mather LE. Clinical pharmacology of local anaesthetics. Anaesth Intensive Care 1980;8: 257-77.

13 Moore DC. Regional block, 4th ed. Springfield: Thomas 1976, 17.

14 Kennedy WF, Bonica JJ, Ward RJ, Tolas AG, Martin WE. Grinstein A. Cardiorespiratory effects of epinephrine when used in regional anaesthesia. Acta Anaesth Scand Suppl 23, 1966; 320-33.

15 Winnie AP. Interscalene brachial plexus block. Anesth Analg 1970; 49: 455-66.

16 Wildsmith JAW, Tucker GT, Cooper S, Scott DB, Covino $B G$. Plasma concentrations of local anaesthetics after interscalene brachial plexus block. Br J Anaesth 1977; 49: 461-6.

17 Vester-Anderson $T$, Christiansen C, Hansen A, Sorensen $M$, Meisler $C$. Interscalene brachial plexus block: area of analgesia, complications and blood concentrations of local anaesthetics. Acta Anaesth Scand 1981; 25: 81-4.

18 de Jong $R H$, Heavner JE. Diazepam prevents local anaesthetic seizures. Anesthesiology 1971; 34: 523-31. 